NBER WORKING PAPER SERIES

\title{
DISBURSING EMERGENCY RELIEF THROUGH UTILITIES: EVIDENCE FROM GHANA
}

\author{
Susanna B. Berkouwer \\ Pierre E. Biscaye \\ Steven L. Puller \\ Catherine Wolfram \\ Working Paper 28818 \\ http://www.nber.org/papers/w28818 \\ NATIONAL BUREAU OF ECONOMIC RESEARCH \\ 1050 Massachusetts Avenue \\ Cambridge, MA 02138 \\ May 2021
}

The views expressed in this article do not necessarily represent the views of the United States or the U.S. Department of the Treasury. We thank Maria Vagliasindi, Arthur van Benthem, and seminar participants at PacDev and UC Berkeley for helpful comments. The DFID Energy and Economic Growth initiative and the TAMU Private Enterprise Research Center generously provided financial support. This study has received Institutional Review Board approval from the University of California at Berkeley (ID 2017-12-10599). To prevent any increased risk of Covid-19 transmission, all surveys conducted by this research team between February 15, 2020 and February 15, 2021 were conducted over the phone. We thank Geetika Pandya and Miranda Lambert for excellent research assistance and Kwame Abrokwah and his team for superbly implementing field activities. The views expressed herein are those of the authors and do not necessarily reflect the views of the National Bureau of Economic Research.

NBER working papers are circulated for discussion and comment purposes. They have not been peer-reviewed or been subject to the review by the NBER Board of Directors that accompanies official NBER publications.

(C) 2021 by Susanna B. Berkouwer, Pierre E. Biscaye, Steven L. Puller, and Catherine Wolfram. All rights reserved. Short sections of text, not to exceed two paragraphs, may be quoted without explicit permission provided that full credit, including $\odot$ notice, is given to the source. 
Disbursing Emergency Relief through Utilities: Evidence from Ghana

Susanna B. Berkouwer, Pierre E. Biscaye, Steven L. Puller, and Catherine Wolfram

NBER Working Paper No. 28818

May 2021

JEL No. H50,H84,O12

\begin{abstract}
$\underline{\text { ABSTRACT }}$
Government transfer programs to distribute food, water, or electricity at low or no cost have been widespread during the COVID-19 global health crisis. How does program design affect the efficiency and distributional implications of these policies? And what design features determine their political popularity? We study these questions in the context of a program to distribute relief through the electric utility in Accra, Ghana, using data from 1,200 households surveyed during the COVID-19 crisis. We find that distributing relief through electricity transfers has significant advantages. It enables an immediate government response to the crisis because it leverages the existing financial infrastructure between the government utility and households. Moreover, theoretical efficiency concerns about in-kind transfers are mitigated because the transfers are inframarginal for most households and electricity credit can be stored, with many even preferring electricity transfers over cash. These advantages do not preclude delays in transfer receipt and the exclusion of some eligible households, and the program is regressive in both design and implementation. The households least likely to receive relief are those who use less electricity, pay a landlord or other intermediary for electricity, or share an electricity meter with other users all common among low-income electricity consumers in urban settings. Finally, transfer receipt increases support for the governing party, but support for the program drops significantly if even a fraction of its costs are to be recovered through future electricity tariff increases. Concerns around disbursing relief through utility transfers in this context thus arise not from efficiency loss, but from regressivity, distributional challenges, and politicization.
\end{abstract}

Susanna B. Berkouwer

The Wharton School

University of Pennsylvania

322 Vance Hall

3733 Spruce Street

Philadelphia, PA 19104

sberkou@wharton.upenn.edu

Pierre E. Biscaye

University of California at Berkeley

Department of Agricultural and

Resource Economics

207 Giannini Hall \#3310 Berkeley,

CA 94720-3310

pbiscaye@ berkeley.edu
Steven L. Puller

Department of Economics

Texas A\&M University

3046 Allen

College Station, TX 77843-4228

and NBER

puller@econmail.tamu.edu

Catherine Wolfram

Haas School of Business

University of California, Berkeley

Berkeley, CA 94720-1900

wolfram@ haas.berkeley.edu

An online appendix is available at http://www.nber.org/data-appendix/w28818 


\section{Introduction}

Governments often take steps to provide for a society's most vulnerable members, particularly during economic downturns or other unanticipated crises. Social protection programs can take the form of direct cash payments (as in social security transfers or unemployment income), in-kind transfers (as in food or emergency supplies), or subsidies for purchases of basic necessities (such as water, healthcare, and energy). As the COVID-19 public health crisis spread, often closely followed by deep economic downturns that disproportionately affected the poor, many governments responded by expanding or introducing transfer programs. The Gentilini, Almenfi, and Dale (2020) global database on responses to the COVID-19 pandemic reports that 215 countries introduced or expanded government social protection programs, including 133 introducing new direct cash payments and 121 providing food or food subsidies. Energy relief programs were common before 2020, but 112 countries increased financial support for utility payments or other financial obligations because of the COVID-19 crisis (Coady et al. 2015; Gentilini, Almenfi, and Dale 2020). Support for utility payments in the energy sector included payment deferrals, targeted energy transfers, and a smaller number of price reductions and price freezes.

The design and implementation of social protection programs can meaningfully affect their overall impact. We assess the efficiency, distributional, and political implications of an electricity relief program announced by the government of Ghana in April 2020 to help residents cope with the public health crisis. The program promised monthly transfers worth $50 \mathrm{kWh}$ (worth $3.50 \mathrm{USD}$ ) for April-June to 'lifeline' customers (those who consumed less than $50 \mathrm{kWh}$ per month at baseline), and monthly transfers worth $50 \%$ of baseline consumption for all other customers (ECG 2020b). The government eventually extended the 50kWh transfers for lifeline customers through March 2021. We discuss the program's design and implementation theoretically, and then use data collected between May and October 2020 across three rounds of surveys, each with more than 1,200 respondents connected to electricity in Accra, to assess them empirically. Our results show that the constraint on consumption bundles imposed by in-kind transfers is largely non-binding, alleviating concerns that these may increase utility less than cash transfers of an equivalent value. On the other hand,

we identify significant regressivity and inefficiency that dampen the program's aggregate welfare gains, and discuss the program's role as a form of clientelism prior to a presidential election.

First, we consider economic efficiency and expediency: does the program maximize utility gains, and do transfers arrive quickly enough to absorb the negative shock from the pandemic? Theoretically, in-kind transfers constrain consumption bundles and may therefore generate lower utility gains than unconstrained cash transfers - but these concerns may not hold in practice (Bruce and Waldman 1991; Currie and Gahvari 2008; Gadenne et al. 2021; Hirvonen and Hoddinott 2021). The transfers in Ghana were almost entirely inframarginal, since transfers were based on March electricity consumption and could be saved indefinitely, and thus theoretically equivalent to cash transfers (Southworth 1945; Cunha 2014). We conduct a value elicitation survey and find that households valued 50 GHS worth of electricity at 50.1 GHS in cash on average. Moreover, 45\% of households valued the electricity more than an equivalent amount of cash for reasons including 
large transaction costs and a demand for commitment. Those who were roughly indifferent often explicitly cited inframarginality as the reason. Inefficiency relative to cash thus did not limit the program's effectiveness.

This is especially encouraging because the government may not have had the capacity to disburse cash transfers broadly (Allotey 2020; IPA 2020). In settings with limited mobile money penetration but broad electricity connectivity, electricity transfers may be implemented more quickly and cost-effectively. By leveraging the existing financial infrastructure for electricity payments, the government avoided the cost and time of establishing or expanding an alternative distribution system. Still, this did not preclude delays or exclusion of designated recipients. We find that only $35 \%$ of households had received a transfer by the end of the first month of the program, and one-third of households still reported never having received any transfers three months later.

Second, building on a large literature studying the distributional impacts of energy transfers (Komives et al. 2008; Basurto, Dupas, and Robinson 2020; Borenstein 2012), we identify numerous channels of regressivity in the program's design and implementation. A transfer proportional to baseline consumption implies larger transfers to households consuming the largest amounts, who are likely wealthier. Households without electricity, who generally have lower incomes, did not receive a cash substitute. Even among connected households, we find that lower-income households - which we proxy for using household characteristics - are less likely to have ever received any relief. Lifeline customers are 19 percentage points less likely to have ever received the transfer even though they were eligible for longer than other households. Households that pay for electricity through an intermediary such as a landlord do not receive the transfer if it is not passed on to them by the intermediary: they are 13 percentage points less likely to have ever received relief.

Finally, we consider the program's clientelistic government objectives prior to Ghana's closely contested December 2020 Presidential election. Satisfaction with the program was $94 \%$ among respondents who had received the transfer, and $72 \%$ among those who had not. In line with existing evidence on the political economy of energy support programs (Kojima, Bacon, and Trimble 2014; Strand 2013; Wolfram et al. 2021), particularly in Ghana (Briggs 2021), transfer receipt increases support for the current governing party. We cautiously interpret this as causal because ex ante political affiliation does not predict receipt, and the results persist even when including respondent fixed effects.

Little attention was paid to the program's significant cost, even though financial sustainability is a widespread concern in Africa, where utilities in only two out of 39 countries are recovering their operational and capital costs (Kojima and Trimble 2016). The government may gain increased political support by asymmetrically emphasizing the benefits without discussing the costs. To quantify this, we prompted respondents to consider that the cost may need to be recovered through higher electricity tariffs in future years. Satisfaction with the transfers fell by nearly $50 \%$. In fact, $52 \%$ of respondents would prefer not to receive any relief even if their electricity costs next year increase by only a quarter as much as the transfers they receive this year.

The paper is organized as follows. We first describe the COVID relief program in Ghana and 
present our sample and data in Section 2. In Section 3 we present a framework for evaluating electricity transfer programs. In Sections 4, 5, and 6, we discuss the efficiency, distributional, and political implications of the relief program, respectively. Section 7 concludes.

\section{Context and Data}

$82 \%$ of households in Ghana are connected to electricity, including $94 \%$ in Accra, the capital. The Electricity Company of Ghana (ECG) is responsible for electricity distributed in southern Ghana, which includes Accra. ECG has just under 4 million customers (ECG 2020c), which they define at the meter level: one individual might have two meters, for example at their home and at their business. Conversely, a single meter may serve multiple households.

ECG registers two meter types. Those with a pre-paid meter (around half of ECG customers) may only consume electricity that they pay for in advance by purchasing electricity credit sold at ECG branches and local shops that act as vendors. Customers on 'smart' pre-paid meters can also buy credits online. Once customers consume their prepaid electricity, their electricity is shut off, and only turned on after they buy credits. Those with a post-paid meter may consume any amount of electricity, and are billed for their consumption, often with a two or three month delay.

\subsection{The COVID electricity relief program}

The first cases of COVID-19 were confirmed in Ghana on March 12, 2020. ${ }^{1}$ On April 9th, the government announced electricity and water relief programs in response to associated economic challenges (Africa Energy Portal 2020). ${ }^{2}$ Ghana's Deputy Minister of Finance noted that the government lacked "a formalized means that allows [it] to deploy cash or intangible benefits to the needy in society," and that water and electricity transfers were among the only options available to extend relief (Allotey 2020). ${ }^{3}$

Eligibility was based on consumption during March 2020 (ECG 2020b). 'Lifeline' customers, who consumed less than $50 \mathrm{kWh}$ in March, would receive $50 \mathrm{kWh}$ in free electricity monthly (worth 3.50 USD) for April through June. ${ }^{4}$ All other customers would receive a transfer worth $50 \%$ of their March consumption. ${ }^{5}$ For example, a customer who consumed $30 \mathrm{kWh}$ of electricity in March would be eligible for transfers worth $50 \mathrm{kWh}$ of electricity each month, while a customer who consumed

\footnotetext{
${ }^{1}$ Figure A1 displays a timeline of these events and our surveying activities (described in Section 2.2).

${ }^{2}$ The government also implemented a program to provide free food and essentials to some households in the largest cities of Accra and Kumasi during the strictest part of the pandemic lockdown (Dadzie and Raju 2020).

${ }^{3}$ Ghana's Livelihood Empowerment Against Poverty (LEAP) Program, introduced in 2008, provides bimonthly cash transfers to over 330,000 households, targeting the extreme poor and mostly focused on northern Ghana. LEAP provided an additional one-off round of transfers to beneficiaries in May (Dadzie and Raju 2020). It is not clear if any expansion of this program during the pandemic would have been feasible.

${ }^{4}$ For comparison, mean monthly household expenditures on electricity, gas, and fuels across all households in Ghana are around 10 USD (Ghana Statistical Service 2019.

${ }^{5}$ Our survey measures March electricity expenditures rather than electricity consumption, which we don't observe. We expect these two to be strongly correlated, but not sufficiently so to be able to employ a regression discontinuity design here.
} 
$120 \mathrm{kWh}$ of electricity in March would be eligible for $60 \mathrm{kWh}$ each month. The government expected to spend 170 million USD between April and June (ECG 2020a; GhanaWeb 2020). In July, the government extended electricity relief for lifeline customers through December 2020. This was later extended through March 2021. Non-lifeline customers were not eligible for transfers after June. The program extension from July through December was expected to cost the government 340 million USD (ECG 2020e).

The mode of the transfer depended on the type of electricity meter used by the household. For post-paid customers, the transfers would automatically be factored into their bills. Customers on 'smart' pre-paid meters would be automatically credited each month. ${ }^{6}$ Customers on non-smart pre-paid meters would receive the transfer the first time they purchased credit each month, with a one month delay, swiping a card on their meter and presenting that card when purchasing electricity to verify their eligibility (ECG 2020e). ${ }^{7}$

\subsection{Sample and Data}

We survey 1,245 ECG customers residing in Accra who had participated in a related study in 2018 and 2019 (Klugman et al. 2019). ${ }^{8}$ Each respondent was surveyed two or three times across three rounds of data collection between May-October 2020. ${ }^{9}$ The survey collected data on household composition, electricity connections and expenditures, electric appliances, expenditures in the last 7 days, food security, credit, government relief, and perceptions of the government. Appendix C includes more detail on the survey and specific variables used in the analyses.

Table A1 compares sample households to urban households in Accra surveyed by the Ghana Statistical Service (GSS). Respondents to our surveys are somewhat younger, as we did not require our respondents to be household heads; otherwise our sample is roughly representative of lowerand middle-income residents of Accra.

Table A2 presents sample summary statistics. $26 \%$ of households pay a third party for electricitythe remainder pays ECG directly. $91 \%$ have a pre-paid meter, and $13 \%$ would be considered lifeline customers using reported electricity expenditures in March to proxy consumption. $46 \%$ of households share a meter, with on average 3 or 4 other users.

In each round, we ask respondents whether they have ever received an electricity transfer, and the amount they received in the last 30 days. While these self-reports could be inaccurate if households receive the transfer without knowing it, this is unlikely for several reasons. First, awareness of the program is high (97.4\% in round 1). Second, respondents have a good sense of their electricity spending, so they should notice a sizeable reduction in electricity costs. Third, pre-paid customers receive itemized receipts - post-paid customers receive itemized bills - and should therefore notice additional credit. Finally, our survey emphasizes the transfer program, so respondents should be

\footnotetext{
${ }^{6}$ Less than $7 \%$ of respondents on pre-paid meters in our sample have a smart meter.

${ }^{7}$ Swiping a card on the meter was not new: it had always been a requirement for topping up.

${ }^{8}$ Figure A2 shows approximate respondent locations.

${ }^{9} 86.5 \%$ of respondents are surveyed in all three rounds; $12.7 \%$ are surveyed in two rounds. Figure A1 displays our surveying timeline.
} 
particularly attentive to whether or not they have received the transfer.

\section{Framework}

Household $i$ derives utility $u_{i}\left(x_{i}, c_{i}\right)$ from electricity consumption $x_{i}$ (in $\mathrm{kWh}$ ) and all other consumption $c_{i}$. Utility is concave in both $x_{i}$ and $c_{i}$. Conditional on exogenous, fixed income $Y_{i}$, define a household's utility maximizing consumption bundle $u_{i}^{*}=u_{i}\left(x_{i}^{*}, c_{i}^{*} ; Y_{i}\right)$. Electricity is a normal good.

Government may provide a lump sum electricity transfer $s$ (in $\mathrm{kWh}$ ) to the household, that is constrained to electricity consumption. The household can choose to consume additional electricity $x_{i}^{s}$ such that total electricity consumption $x_{i}=x_{i}^{s}+s$, with $x_{i}^{s} \geq 0$ and $s \geq 0 .{ }^{10}$

Efficiency implication: Define $u_{i}\left(x_{i}^{T}, c_{i}^{T}\right)$ to be the utility from the optimal bundle under a cash transfer with the same value as $s$. Constraining expenditures to electricity reduces welfare whenever $s>x_{i}^{T}$ :

$$
u_{i}\left(x_{i}^{T}, c_{i}^{T}\right)>u_{i}\left(s, c_{i}^{s}\right) \forall s>x_{i}^{T}
$$

If the transfer is inframarginal $\left(s \leq x_{i}^{T}\right)$, then the optimal bundle lies within the possible set, and an electricity transfer generates the same welfare gain as an unconstrained cash transfer:

$$
u_{i}\left(x_{i}^{T}, c_{i}^{T}\right)=u_{i}\left(x_{i}^{s}+s, c_{i}^{s}\right) \forall s \leq x_{i}^{T}
$$

The impact on utility of an electricity transfer relative to an equivalent cash transfer is therefore an empirical question. When electricity transfers do not exceed optimal consumption levels $(s \leq$ $\left.x_{i}^{*}\right)$, cash and electricity transfers are equivalent, as the electricity transfer replaces inframarginal expenditures. This is likely the case in Ghana, where the transfer amount is a function of baseline consumption. While optimal electricity consumption may fall during a crisis, and while lifeline households were eligible for transfers of $50 \mathrm{kWh}$ which were not inframarginal, these concerns may be alleviated given that the monthly transfers did not expire if not immediately consumed.

For Ghana's electricity relief, the transfer is a function of household $i$ 's baseline electricity consumption, denoted $x_{i 0}$ :

$$
s_{i}= \begin{cases}50 & x_{i 0} \leq 50 \\ \frac{x_{i 0}}{2} & x_{i 0}>50\end{cases}
$$

Given $\frac{\partial x_{i}}{\partial Y_{i}}>0$, for $x_{1}>x_{2}$ we have $Y_{1}>Y_{2}$. Define low, middle, and high income households as $x_{L}<50<x_{M}<100<x_{H}$.

\footnotetext{
${ }^{10} s$ may be negative in the case of an electricity tax. This is common among many utilities, but we abstract away from this here. One can consider the price of electricity as inclusive of any taxes.
} 
Distributional implication 1: Higher income households receive higher transfers $\left(s_{L}<s_{H}\right)$.

Next we consider the case where the government disburses the relief to an intermediary, who then determines the share $\alpha_{i} \in[0,1]$ to transfer to household $i$. The remainder, $\left(1-\alpha_{i}\right) s_{i}$ is retained by the intermediary. If the intermediary charges a fixed monthly rate for electricity to its tenants, and does not modify this to account for her reduced electricity costs, then $\alpha_{i}=0$.

Distributional implication 2: Incomplete pass-through $\left(\alpha_{i}<1\right)$ exacerbates regressivity when intermediaries have higher incomes than intended recipients.

In Ghana, many households pay a landlord or other household for their electricity rather than paying the utility directly themselves. Incomplete pass-through has regressivity implications, as households that pay an intermediary are less wealthy on average than intermediaries.

\section{Efficiency}

Do transfers reach recipients and increase utility efficiently and expediently? The economic efficiency of in-kind transfers is often benchmarked against unconditional cash transfers (Haushofer and Shapiro 2016). Concerns that cash transfers increase inflation or spending on temptation goods have been largely assuaged by recent research (Egger et al. 2019; Handa et al. 2018). If the inkind transfer amount is no greater than the unconstrained utility-maximizing expenditure, then the transfer is inframarginal; if not, the cash transfer dominates. Yet, in-kind transfers may have significant advantages in certain contexts (Bruce and Waldman 1991; Cunha, De Giorgi, and Jayachandran 2018; Currie and Gahvari 2008; Gadenne et al. 2021; Hirvonen and Hoddinott 2021). For example, absent a direct financial relationship between government and households, in-kind transfers can leverage existing infrastructure. In-kind transfers may also offer protection against price volatility of the transferred good, though that is less relevant for electricity transfers as prices do not typically fluctuate except for infrequent tariff structure changes. The efficiency of in-kind transfers relative to cash transfers is thus an empirical question.

\subsection{Constraints on consumption}

The electricity transfer is unlikely to be inframarginal for most lifeline customers, who consumed less than $50 \mathrm{kWh}$ in March but received $50 \mathrm{kWh}$ in relief each month. On the other hand, nonlifeline customers received $50 \%$ of baseline electricity consumption in relief each month. During an economic crisis, consumption may not be constant. But if optimal consumption does not fall significantly over time, the transfers will be inframarginal for these customers, suggesting minimal efficiency loss from transferring electricity instead of cash.

To investigate this, we implement a contingent valuation method using an iterated sequence of hypothetical dichotomous choices to elicit respondent willingness to pay (WTP) for a 50 GHS 
electricity transfer. ${ }^{11}$ The respondent is asked to choose whether they would prefer to receive a 50 GHS electricity transfer or a cash transfer of a certain amount, which varies depending on the prior response. WTP is the highest cash transfer amount the respondent rejects in favor of the electricity transfer. This approach is commonly used to elicit WTP for goods or services (Alberini and Cooper 2000), including for electricity in different African countries (Abdullah and Jeanty 2011; Deutschmann, Postepska, and Sarr 2021; Sievert and Steinbuks 2020). Appendix C includes a detailed description of the elicitation method.

Figure 1 shows the results. The median household values 50 GHS of electricity at 35-50 GHS in cash, ${ }^{12}$ and the mean value across households is 50.1 GHS. $45 \%$ prefer the electricity transfer to an equivalent or larger amount of cash.

\section{[ Figure 1]}

Respondents who prefer the electricity transfer over an equal or larger amount in cash provide several reasons. The most common reason is that they "would use the money for electricity anyway" (62\%), indicating that an electricity transfer covers inframarginal expenditures for many households. Second, transaction costs are high-most pre-paid customers must visit a vendor to purchase electricity credit. $19 \%$ of respondents who prefer electricity to cash state that "it takes too much time/effort to top up electricity". ${ }^{13}$ Some indicate a desire for commitment: $36 \%$ of respondents "worry that [they] will spend the money on something else". Indeed, customers who received the transfer are slightly less likely to have their power shut off due to failure to purchase credit, and are more likely to say they are consuming more electricity than before the crisis. ${ }^{14}$

On the other hand, a sizeable percentage of respondents strongly prefers cash to electricity: $20.1 \%$ of respondents would prefer 25 GHS in cash to 50 GHS in electricity. These may be liquidityconstrained or low users of electricity. Panel A of Figure 1 suggests lifeline customers are more likely to prefer cash to an electricity transfer, but the difference between these customer types is not very large. This may be because unused electricity credit can be saved for future months, so the transfer could be considered inframarginal over a long enough time frame, even for lifeline customers.

Panel B of Figure 1 shows that respondents who pay a landlord or other intermediary for electricity strongly prefer cash over electricity. They may not trust that the intermediary will pass on the full transfer (we discuss this in Section 5.2). Those who had never received the electricity relief have a greater preference for cash - they may not trust that they will receive the transfer.

\footnotetext{
${ }^{11} 50$ GHS, or 8.60 USD, is roughly the median and mean monthly transfer expected in our sample.

${ }^{12}$ This indicates that the respondent prefers receiving 50 GHS in cash to 50 GHS in electricity, but prefers receiving 50 GHS in electricity to 35 GHS in cash. We did not offer choices involving cash transfers between 35-50 GHS.

${ }^{13}$ For pre-paid meter customers, electricity transfers could also reduce the number of trips to buy electricity and reduce potential exposure to COVID-19.

${ }^{14}$ The marginal cost of electricity generation in Ghana is difficult to estimate, particularly in a context where the plurality of electricity is generated using hydroelectric power. But when electricity is highly subsidized as in Ghana, the marginal cost of generation may exceed marginal benefit, and increased consumption could lower social welfare. While it is unlikely that this is the case, given that most consumers are at the steep part of the utility function, we nonetheless refrain from quantifying welfare impacts along this dimension.
} 
In the aggregate, households do not have a clear preference for cash over an electricity transfer, suggesting limited efficiency losses from providing relief through an electricity transfer. Even lifeline households only have a modest preference for cash. These results echo a small recent literature reporting stated respondent preferences for transfers in-kind rather than in cash in low-income contexts (Gadenne et al. 2021; Gentilini 2016; Hidrobo et al. 2014; Hirvonen and Hoddinott 2021; Khera 2014), and other work showing preferences for government-provided public goods over cash (Khemani, Habyarimana, and Nooruddin 2019; Sandefur, Birdsall, and Moyo 2015). To our knowledge ours is the first paper to demonstrate this result for a private good other than food. This should assuage concerns about inefficiency relative to cash.

\subsection{Implementation efficiencies}

After implementing strong restrictions on movement and business when the pandemic hit Ghana, the government sought to distribute relief as quickly as possible. By working through existing transfer systems or markets, governments without existing cash transfer structures circumvent the need to set up novel transfer systems, which could hasten relief. Ghana does not have existing systems to easily and broadly provide cash transfers to households (Allotey 2020; IPA 2020), meaning cash transfers would have been costly and slow. ${ }^{15}$ Meanwhile, ECG has a direct financial relationship with about 4 million customers (ECG 2020c), which allowed some households to begin receiving relief on May 1, only 1.5 months after the first confirmed COVID-19 case in Ghana, ${ }^{16}$ and $46 \%$ of households surveyed in May had received a transfer.

Still, most households experienced delays and many never received relief. By the final survey round in September-October, 31\% of respondents reported still having never received any relief (Figure 2). This contrasts to ECG reports, which by May claimed $99.98 \%$ of pre-paid customers had received their benefits (ECG 2020c). 8.5\% of respondents who never received a transfer attributed this to government corruption. While $50 \%$ of households who had not received any transfers in May stated they thought their transfer was likely delayed, by September fewer than $20 \%$ attributed their non-receipt to delays. Instead, almost half of respondents thought it was due to government incompetence.

\section{[ Figure 2 ]}

In July the program was extended for lifeline electricity customers only. We observe a sharp fall in the share of households receiving the transfer in the last 30 days starting in August, even for lifeline customers, which raises questions about the implementation of this rule (Figure 2). ${ }^{17}$

\footnotetext{
${ }^{15}$ Livelihood Empowerment Against Poverty (LEAP) provides monthly cash transfers to over 330,000 poor households (primarily in northern Ghana), but reaching this population required many years of outreach. The costs of expanding this program during the pandemic may have been high.

${ }^{16}$ For comparison, the time between the first confirmed COVID-19 case in the United States and the start of distribution of relief checks under the CARES Act was also around 1.5 months.

${ }^{17}$ We proxy lifeline status with March electricity expenditures for households, while actual lifeline status was determined at the meter level based on March consumption.
} 
It is unclear whether attempts to provide relief through a different channel would have been more effective. The lack of existing alternatives suggests any other mechanism would likely have caused delays and limited receipt. Indeed, the other main relief program implemented by the government was a free water program, and an analysis by the GSS finds that $78 \%$ of communities did not receive free water (Ammah 2020).

Technical aspects of the distribution process may have contributed to non-universal receipt, though no single explanation can account for the entire gap. First, ECG notes that some prepaid customers failed to swipe their cards on their meters to verify their transfer eligibility (ECG 2020c). But this was already a requirement for pre-paid topups even before the relief program, and an experiment where we provide this information to a random subset of participants did not show increased receipt, so it is unlikely that this can explain a large share of non-receipt. Second, while delayed bills may have delayed transfer receipt initially, only half of post-paid customers had received any transfers by October, even though by then nearly all post-paid customers had received bills for April. ${ }^{18}$ Third, ECG indicated that customers who had tampered with their meters did not receive transfers in May (ECG 2020d), however there is no indication that meter tampering is widespread in Accra. Finally, relief for pre-paid customers was conditional on purchasing credit, but pre-paid customers in our sample topped up electricity 1.9 times per month on average, and fewer than $6 \%$ indicated that it had been more than a month since their last purchase, with no difference in the mean number of days since the last electricity purchase between those that did and did not receive the transfer.

In addition to these technical aspects, the targeting of transfers to electricity meters rather than households may also account for some of the gap in relief coverage we observe. $46 \%$ of households in our sample share a meter and $26 \%$ pay an intermediary for electricity, meaning another party may capture the transfer for the meter used by these households. In this case, while the transfer may reach the meter as intended, it does not reach all households using the meter. By AugustOctober $74 \%$ of households that pay for electricity directly had received relief, compared to $53 \%$ of households that pay an intermediary (Figure 2). We discuss this further in Section 5.2.

Ultimately, while the electricity transfer program had some shortcomings in implementation, it successfully transferred aid to the majority of households in Accra. A cash transfer program to disburse aid in response to the pandemic rapidly and to such a large population might not have been feasible.

\section{Distributional implications}

Next we consider the program's distributional implications. An obvious concern with providing relief through electricity is that households without a connection are excluded. $18 \%$ of Ghanaian households, and $25 \%$ of rural communities, are not connected to the electricity grid, and they did

\footnotetext{
${ }^{18}$ It is unlikely that many respondents received transfers without realizing given the salience of electricity costs, widespread awareness of the program (97.4\% in round 1), and prompting by surveyors to review their bills and spending.
} 
not receive a substitute for the electricity transfer (Ammah 2020; The World Bank 2018).

\subsection{Regressivity in transfer amount and receipt}

Among those with access to electricity, a transfer that is proportional to baseline consumption will imply larger transfers to those who consumed more electricity, who are often wealthier households. ${ }^{19}$ Lifeline customers at baseline receive $50 \mathrm{kWh}$ in electricity each month. All other customers receive a transfer worth $50 \%$ of their baseline consumption. Those with baseline consumption above 100 $\mathrm{kWh}$ per month are therefore eligible for the highest transfers. In this respect, the extension of the relief program after the first three months for lifeline customers only is less regressive.

Program implementation was also regressive. Table 1 shows that lifeline customers are 18 percentage points less likely to have ever received the electricity transfer. Ownership of electric appliance types - a proxy for household wealth - is also significantly associated with transfer receipt. ${ }^{20}$

\section{[ Table 1 ]}

Even though the program was extended for lifeline households only after July, Figure 2 Panel A shows that the gap in transfer receipt by lifeline status narrows only slightly even after July. If households that consumed less electricity at baseline have lower incomes, lower transfer receipt for lifeline households implies regressive implementation.

\subsection{Distribution via an intermediary}

When transfers are distributed via an intermediary (e.g., distributors transporting food to markets, water flowing via utilities and landlords, or agricultural inputs distributed by community leaders), the risk exists that they skim a portion of the transfer value. Households that do not directly pay ECG for electricity will not receive the transfer unless it is passed through. Table 1 shows that respondents who buy electricity from a landlord or another household are 12.5 percentage points less likely to have ever received the transfer. Figure 2 shows that this gap persists over time, suggesting it is not driven by intermediaries taking longer to pass on the transfer. Table A3 shows that households that pay a landlord own fewer appliance types and generators, suggesting that these households have lower incomes and less wealth on average than landlords or households that manage meters.

Imperfect pass-through may occur for several reasons. Households depend on their intermediary to accurately report transfer receipt. Households may know to ask for rebates, but only the intermediary observes electricity consumption and transfer receipt. This is compounded by the fact that many meters are used by multiple households, reducing their ability to estimate transfer eligibility. Second, $53 \%$ of households that pay an intermediary for electricity report paying a fixed periodic

\footnotetext{
${ }^{19}$ In the US, some suggest that the relationship between income and electricity consumption may turn negative among higher income households due to insulation and energy efficiency adoption, but there is little empirical evidence of this (Borenstein 2012), and it is unlikely to hold in Ghana.

${ }^{20}$ Because all surveys were conducted over the phone, direct questions on household wealth were excluded.
} 
amount. If the landlord does not change the amount charged to meter users to reflect that she pays less for the electricity due to the transfer program, the benefit will accrue entirely to the landlord. Even if some households know to ask for a lower payment, the terms of their rental or meter use agreement may rule out a rebate.

We observe a similar result when considering the government's water relief program, the other main government response to the pandemic. Respondents who pay a landlord for electricity (assumed more likely to also pay the landlord for other utilities such as water) are 10 percentage points less likely to have ever received the water transfer (Table A4).

\subsection{Housing structures}

Additional regressivity may arise through the design of housing structures. It is common in Accra for multiple families to share a meter. $29 \%$ of respondents who pay ECG for electricity share a meter with at least one other user ( $5 \%$ share with five or more other users), while $98 \%$ of households who pay an intermediary share their meter with other users (32\% share with 5 or more other users). ${ }^{21}$ $72 \%$ of lifeline households share a meter with at least one other user, compared to $42 \%$ of nonlifeline customers. These households might individually be considered lifeline and therefore eligible for the full transfer if they had their own meter. However, because they share a meter, the combined monthly consumption of all users may exceed the lifeline threshold, warranting only a $50 \%$ relief rather than the $50 \mathrm{kWh}$ transfer that their individual household consumption would warrant.

Table 1 indicates that respondents who share their meter with other users are around 6 percentage points less likely to have ever received the transfer; this is primarily driven by households that pay a landlord. These households do not appear to receive significantly smaller transfers conditional on receipt, though this might be because lifeline households - whose transfers might be lower as a result of sharing a meter - are less likely to receive the transfer at all and so are excluded from this calculation. Among households that received the transfer in the last 30 days, those with a shared meter report receiving 8.87 USD in the last 30 days, compared to 9.22 USD for households that do not share a meter.

\section{Political Implications}

The provision of public goods prior to an election has frequently been found to increase support for the incumbent (Ferraz and Finan 2008; Casey 2015; Wolfram et al. 2021). The government of Ghana gained significant political support months before the December 2020 presidential election by implementing a large multi-month electricity relief program. We show that this is due to widespread support for the program together with partial obfuscation of its significant costs.

\footnotetext{
${ }^{21}$ Households that pay a landlord for electricity are 63 percentage points more likely to share a meter, controlling for other household characteristics.
} 


\subsection{Program support}

Support for the program is high: $94 \%$ of respondents who had received transfers, and $72 \%$ of those who hadn't, indicated satisfaction with the program (Figure A3). Columns 1-3 of Table 2 show that transfer receipt increases support for the incumbent- the New Patriotic Party (NPP)-by 7-8\% relative to households that never received the transfer. Transfer recipients are 11 percentage points more likely to support NPP (relative to the opposition or neutrality), a $21 \%$ increase relative to non-recipients (Table A6). Given that the NPP won the election by about 4 percentage points nationally, these political gains are substantial.

The magnitudes are similar with and without controlling for prior support for NPP (Table 2), and when considering other measures of respondent political perspectives (Table A5). ${ }^{22}$ These gains are driven by neutral respondents shifting towards favoring NPP, with a smaller reduction in proopposition attitudes. The effect of receiving the transfer in the last 30 days is slightly larger than the effect of receiving it earlier.

[ Table 2 ]

We cautiously interpret these results as causal for two reasons. First, even within households, transfer receipt increases government support, though the magnitudes are smaller (Column 4 of Table 2), alleviating concerns about omitted variables that vary across recipients. Second, Table A7 replicates column 4 of Table 1 adding controls for political perspectives collected during 2018-2019 surveys. $^{23}$ Baseline political support does not affect transfer receipt, ruling out reverse causality.

\subsection{Program cost}

Support for the program depends crucially on household inattentiveness to associated budgetary costs. Program expenditures were expected to be around 511 million USD for the first eight months, representing 1\% of Ghana's 2019 GDP, and 3.4\% of 2019 government expenditures (Ofori-Atta 2019). ${ }^{24}$ Critics argued that it was a populist move by the government ahead of elections, taken with little regard for its impact on government expenditures (Allotey 2020). The Africa Centre for Energy Policy feared the transfers would exacerbate ECG's existing financial challenges (GhanaWeb 2020).

The government has not publicly discussed how it will finance program expenditures. To test whether attention to costs reduces support of the program, we present households with a hypothetical scenario in which ECG increases electricity tariffs proportionally to recover costs. Satisfaction falls by nearly $50 \%$ (Figure A3), and $79 \%$ of respondents would not want any electricity relief, if the amount received this year is exactly offset by an increase in electricity costs next year (Table A8).

\footnotetext{
${ }^{22} \mathrm{~A}$ description of the political variables included in our analysis is included in Appendix C.

${ }^{23}$ The sample size is lower because only a randomly selected half of respondents completed these surveys. Mean transfer receipt and correlations between household characteristics and transfer receipt are similar for this subset compared to the rest of the sample.

${ }^{24}$ The US Government spent over 2 trillion USD on the CARES Act COVID-19 relief program, 45\% of total government spending in the fiscal year ending September 2019 Berger 2020.
} 
We use an incremental guided search to elicit respondent WTP for current electricity transfers in terms of increased electricity costs next year. The approach is similar to the method described in subsection 4.1 and is described in detail in Appendix C. Respondents choose whether they prefer to receive an electricity transfer today and repay some proportion in one year through temporary increases in electricity costs, or to not receive anything. The highest proportion of the transfer the respondent is willing to pay through increased electricity costs is taken as they WTP for the transfer.

Figure 3 shows that most respondents (52\%) would not even accept paying a quarter of the transfer amount in extra electricity costs next year to receive relief. The initial widespread satisfaction with the relief program indicates inattention by households to potential future costs, or the hope that those costs would be borne by others.

\section{[ Figure 3 ]}

The aversion to increased future costs could reflect generic intertemporal preferences or be specific to electricity. To test this, we offer respondents numerically equivalent options for a cash loan. WTP is substantially higher than for electricity. Fewer households reject a loan if they have to repay the same amount next year $(41 \%)$ than reject electricity relief under the same conditions (79\%). $50 \%$ of respondents are willing to take a loan even if repayment includes interest- $12 \%$ of respondents are willing to take a loan even with $75 \%$ annual interest. Aversion to debt or uncertainty about future liquidity therefore cannot fully explain the rejection of electricity transfers under repayment. Those who reject electricity transfers if the same amount must be repaid are much more likely to cite uncertainty about their financial situation next year than those who reject the loan (51\% to 6\%; Table A8). This may reflect mental accounting-respondents may budget for fixed monthly electricity spending (Thaler 1999) — or higher disutility from not paying electricity bills than delays in loan repayment. Finally, this reaction also reflects dislike for unfairness (Kahneman, Knetsch, and Thaler 1986): 47\% would reject the transfer in a repayment scenario due to objections to having to repay something that has been presented to them as free.

Very few respondents $(6 \%)$ reject the electricity transfer because they do not believe they would receive the full electricity transfer, and the distribution of responses to the electricity repayment offers does not vary with transfer receipt or by whether the respondent pays for electricity directly or via an intermediary. ${ }^{25}$

In sum, respondents exhibit strong negative reactions to reminders that the government will somehow need to recover the program's costs, and place greater weight on the cost of increasing their future electricity spending than on the benefit of decreasing their current electricity spending. Government decisions about cost recovery, and ex ante beliefs about recovery methods, will have significant implications for the political support of the program.

\footnotetext{
${ }^{25}$ Transfer receipt and amount have no significant relationship with transfer tradeoff decisions, but respondents that are more satisfied with the relief program are less likely to reject the transfer (Table A9).
} 


\section{Conclusion}

We evaluate the efficiency, distributional, and political implications of an electricity relief program in Ghana that was implemented in response to the economic distress caused by the COVID-19 public health crisis. First, we find that respondents value electricity transfers similarly to an equivalent cash transfer on average, in part because the transfer was inframarginal to counterfactual electricity consumption. Working through the utility's existing customer relationships furthermore circumvented the need to establish a novel cash transfer infrastructure. Despite this expediency advantage, a large proportion of households report never receiving any electricity transfer, potentially due to logistical, technological, and informational reasons.

Second, the program is regressive in design and implementation. Households consuming more electricity receive larger transfers during the first phase of the program, and lifeline customers are less likely to have ever received electricity transfers, despite the program's supposed targeting of this group for over half the program duration. Distribution appears to have been generally regressive, and not simply because poorer households are more likely not to have an electricity connection. Lower-income and less wealthy households, as proxied by paying a landlord for electricity, sharing a meter, spending below the lifeline amount for electricity in March, and having fewer different appliance types, are less likely to have ever received any transfers. Incomplete pass-through of transfer to households who pay an intermediary for electricity may account for part of the gap in relief coverage we observe.

Finally, the transfer program increased public support for the incumbent party in an election year. This support wanes when respondents are asked to consider the possibility that electricity tariffs may increase to fund program costs. Most respondents would prefer to not receive any electricity transfers this year if they have to repay even a fraction of it next year.

This analysis generates several tangible policy findings. First, a uniform rather than a proportional electricity transfer would be more progressive, and possibly easier and less costly to implement. This would also have the advantage that all households would know the amount they were entitled to receive, which might increase pass-through by intermediaries to customers that do not pay for electricity directly. Inframarginal transfers are less likely to be distortionary, but this concern may be less important when the good can be stored, as is the case with most electricity credit. Second, programs where transfers are disbursed to units other than households should attend to the possible exclusion of certain categories of households. Mechanisms incentivizing intermediaries to pass on aid to households would improve the reach of such programs. Third, the program's political support depends on how the costs are eventually distributed. Further research is needed to determine whether the benefits of a government electricity transfer outweigh its costs during an economic crisis, when compared with both a cash transfer or no electricity relief program at all. 


\section{Figures}

Figure 1: Distribution of willingness to pay for a 50 GHS electricity transfer

(a)

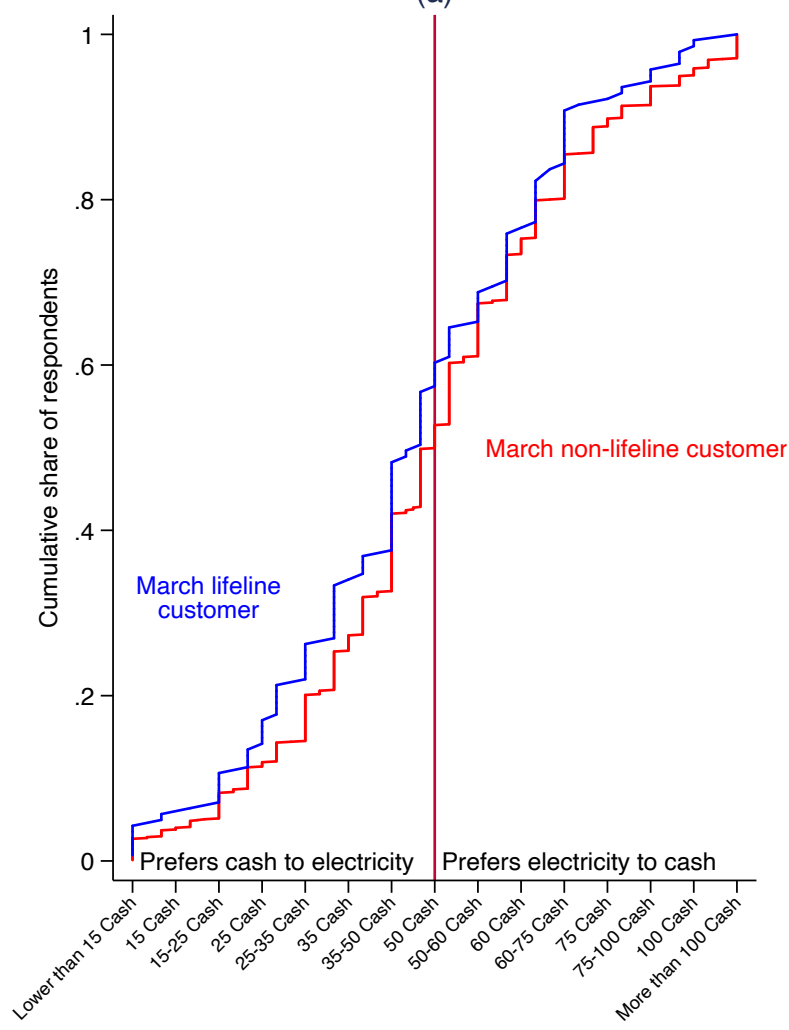

(b)

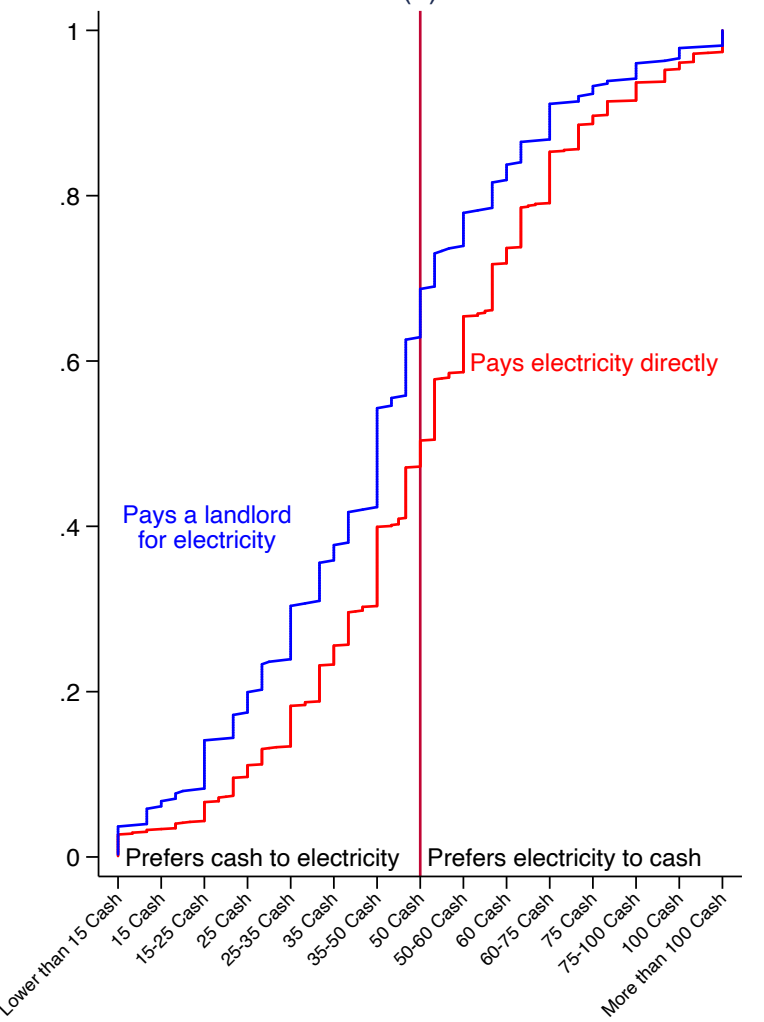

The figures show the distribution of the highest offered cash transfer amount which respondents would reject in favor of a 50 GHS electricity transfer, during an elicitation exercise where respondents are prompted with a series of hypothetical choices between receiving a 50 GHS electricity cash transfer or receiving a specific cash transfer amount. The red bar indicates valuing cash and an electricity transfer equally. Households to the right of the red bar rejected cash transfers larger than 50 GHS, preferring a 50 GHS electricity transfer. Values are mean willingness to pay within households across rounds. Panel (a) compares the distribution by whether households are considered 'lifeline' based on their March 2020 electricity spending. Panel (b) compares the distribution by whether households pay for their electricity directly to ECG or via an intermediary such as a landlord. 
Figure 2: Share of respondents receiving electricity relief, by payment method and lifeline status

(a) Ever received relief

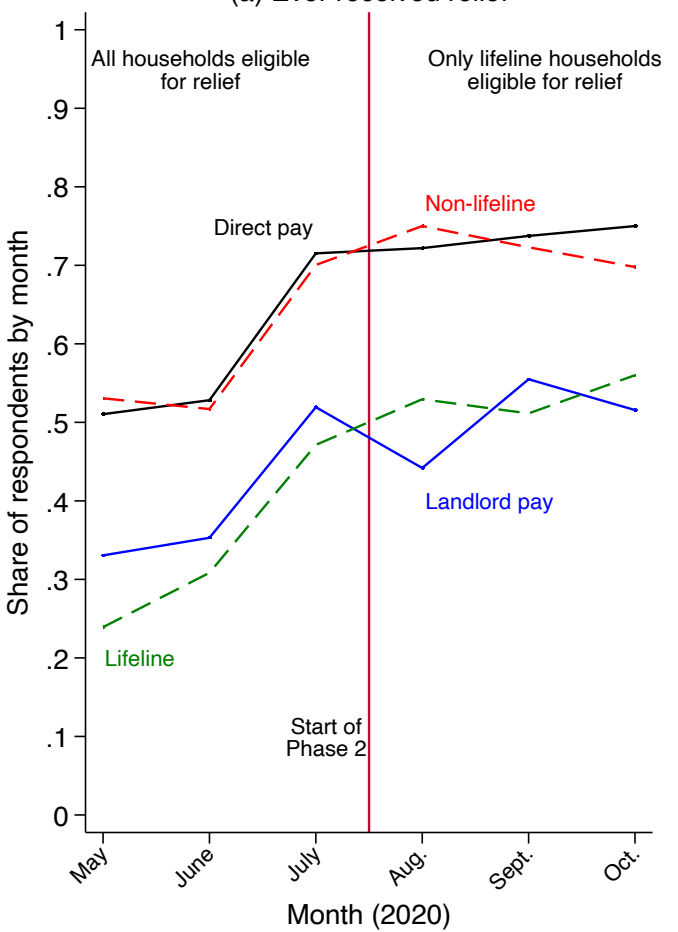

(b) Received relief in last 30 days

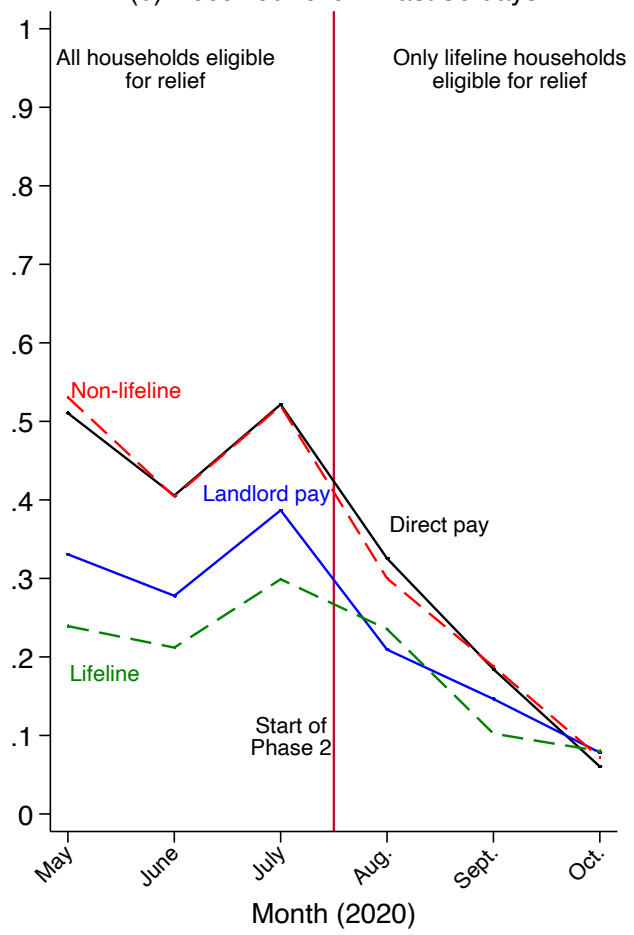

The relief program was announced April 9, 2020 and the first transfers were made on May 1. The red bar indicates the transition from phase 1 to phase 2 of the program. Lifeline status is proxied by reported March electricity expenditures being below the cost of $50 \mathrm{kWh}$, the lifeline threshold. 'Landlord pay' includes payment to any intermediary for electricity, while 'Direct pay' indicates paying for electricity directly to the utility or their agent. 
Figure 3: Distribution of highest amount willing to repay in one year's time for a cash loan or electricity transfer today

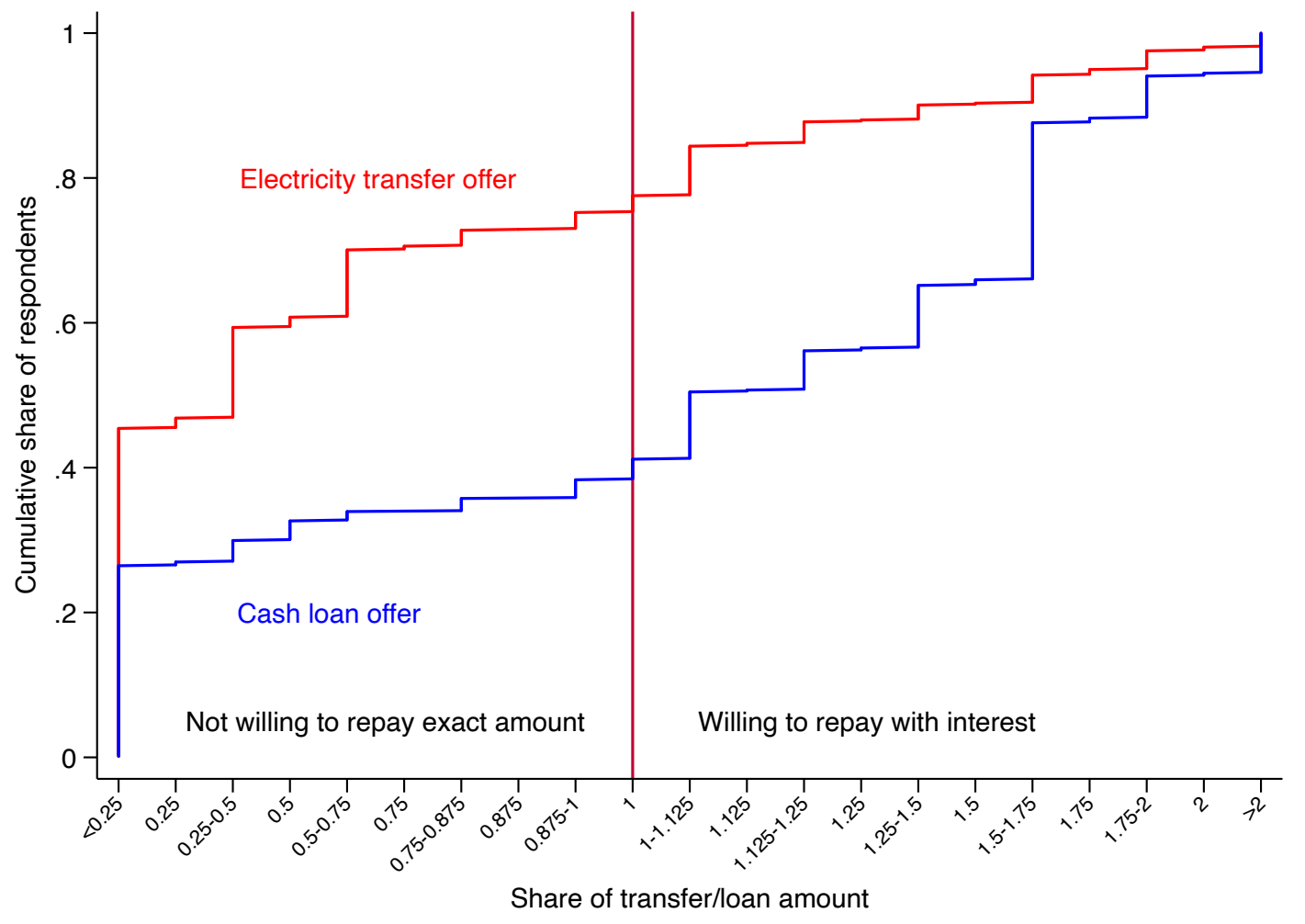

Respondents are presented an iterated sequence of dichotomous choices between either receiving a cash loan or electricity transfer today and repaying some share in one year's time, or receiving nothing. The red bar indicates being willing to repay the exact amount of the transfer or loan in one year. Households to the right of the red bar are willing to repay the loan or transfer today with interest in next year while households to the left of the red bar are only willing to accept the loan or transfer today if they repay less than the principal. The offered transfer amount in the electricity repayment scenario varied by respondent to reflect their actual or expected relief under the government pandemic relief program. The median amount offered was 240 GHS and the mean was 300 GHS. In the generic loan scenario, respondents were randomly offered a loan of either 120, 240, or 360 GHS. 


\section{Tables}

Table 1: Correlates of electricity transfer receipt

\begin{tabular}{|c|c|c|c|c|c|c|}
\hline & $(1)$ & $(2)$ & $(3)$ & $(4)$ & $(5)$ & $(6)$ \\
\hline Pays landlord/other household for electricity & $\begin{array}{c}-0.190^{* * *} \\
(0.029)\end{array}$ & $\begin{array}{c}-0.160^{* * *} \\
(0.033)\end{array}$ & $\begin{array}{c}-0.145^{* * *} \\
(0.032)\end{array}$ & $\begin{array}{c}-0.145^{* * *} \\
(0.033)\end{array}$ & $\begin{array}{c}-0.125^{* * *} \\
(0.034)\end{array}$ & \\
\hline Prepaid meter & & $\begin{array}{c}0.203^{* * *} \\
(0.049)\end{array}$ & $\begin{array}{c}0.198^{* * *} \\
(0.049)\end{array}$ & $\begin{array}{c}0.195^{* * *} \\
(0.049)\end{array}$ & $\begin{array}{c}0.214^{* * *} \\
(0.052)\end{array}$ & $\begin{array}{c}0.248^{* * *} \\
(0.066)\end{array}$ \\
\hline Electricity spending in March (USD) & & $\begin{array}{c}0.001 \\
(0.001)\end{array}$ & $\begin{array}{c}0.000 \\
(0.001)\end{array}$ & $\begin{array}{c}0.000 \\
(0.001)\end{array}$ & $\begin{array}{c}-0.001 \\
(0.001)\end{array}$ & $\begin{array}{c}-0.001 \\
(0.001)\end{array}$ \\
\hline Sum of appliance types held & & & $\begin{array}{c}0.016^{* * *} \\
(0.004)\end{array}$ & $\begin{array}{c}0.016^{* * *} \\
(0.004)\end{array}$ & $\begin{array}{c}0.015^{* * *} \\
(0.004)\end{array}$ & $\begin{array}{c}0.018^{* * *} \\
(0.004)\end{array}$ \\
\hline Lifeline customer according to March spending & & & & & $\begin{array}{c}-0.186^{* * *} \\
(0.043)\end{array}$ & $\begin{array}{r}-0.198^{* * *} \\
(0.045)\end{array}$ \\
\hline Shares meter with other users & & & & & & $\begin{array}{c}-0.062^{* *} \\
(0.028)\end{array}$ \\
\hline Observations & 3339 & 3098 & 3098 & 3092 & 3055 & 2898 \\
\hline Dep. Var. Mean & 0.594 & 0.603 & 0.603 & 0.603 & 0.604 & 0.604 \\
\hline Additional Controls & No & No & No & Yes & Yes & Yes \\
\hline
\end{tabular}

The dependent variable is a dummy for ever having received an electricity transfer at the time of the survey. SEs clustered at household level. Week and day of week fixed effects included but not shown. Additional controls included in columns 4-6 include respondent gender and age, counts of adults and children in the household, whether the household also operated a business at the same location when the household was originally surveyed in 2018-19, and whether the household has a generator. 
Table 2: Respondent political perspectives and transfer receipt

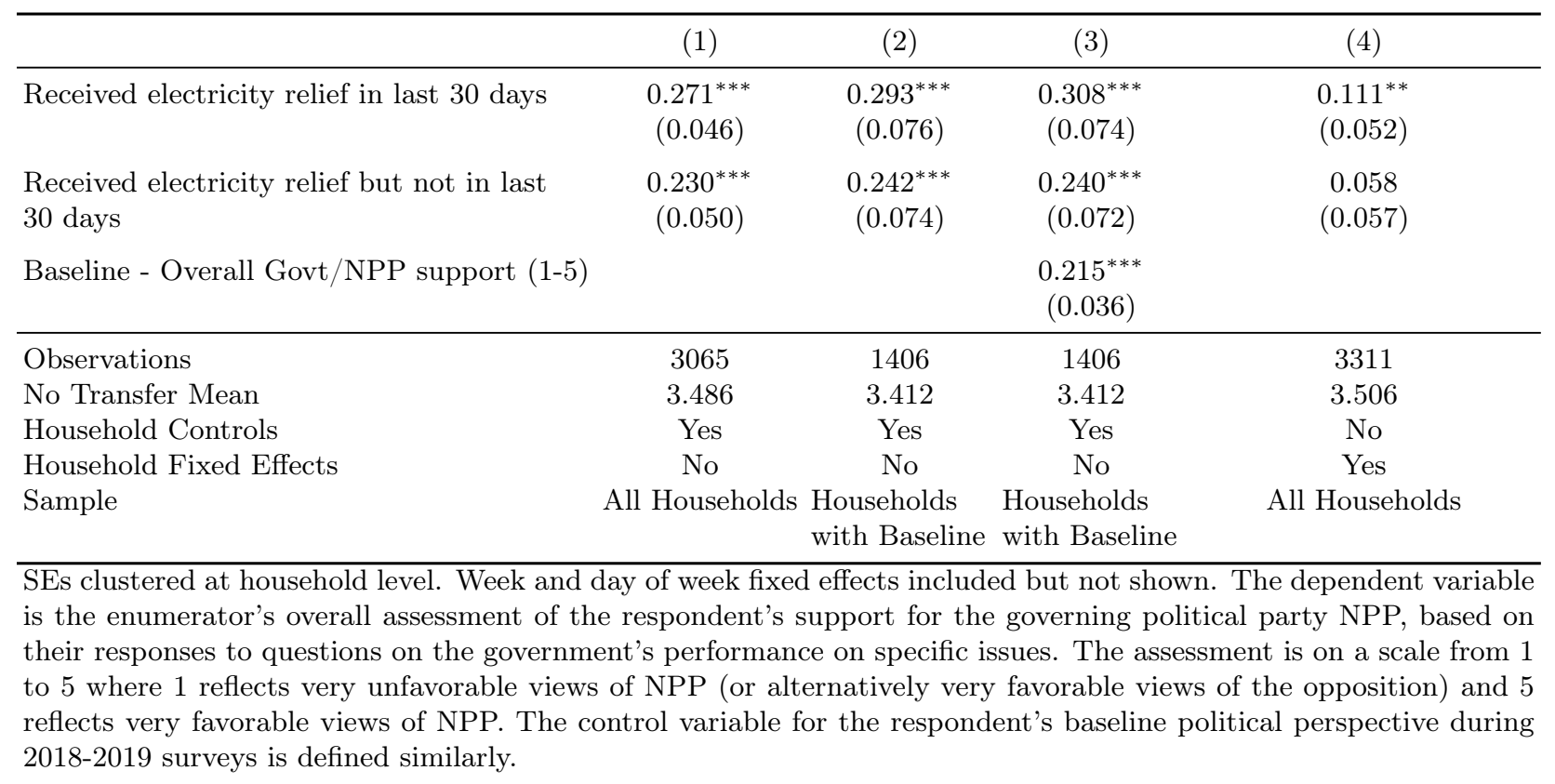




\section{References}

Abdullah, Sabah, and P Wilner Jeanty. 2011. "Willingness to pay for renewable energy: Evidence from a contingent valuation survey in Kenya". Renewable and sustainable energy reviews 15 (6): 2974-2983.

Africa Energy Portal. 2020. Ghana: Government to absorb electricity bills for the poor, others to enjoy 50\% slash. https://africa-energy-portal .org/news/ghana-government-absorbelectricity-bills-poor-others-enjoy-50-slash.

Alberini, Anna, and Joseph Cooper. 2000. Applications of the contingent valuation method in developing countries: A survey. Vol. 146. Food \& Agriculture Org.

Allotey, Godwin Akweiteh. 2020. Government justifies extension of free water, electricity to Ghanaians. https : / / citinewsroom . com/2020/07/government - justifies - extension - of - free water-electricity-to-ghanaians/.

Ammah, Nii Armah. 2020. COVID-19: 78\% of communities did not benefit from government's free water - GSS. https://citinewsroom . com/2020/09/covid-19-78-of - communities-didnot-benefit-from-governments-free-water-gss/.

Basurto, Maria Pia, Pascaline Dupas, and Jonathan Robinson. 2020. "Decentralization and efficiency of subsidy targeting: Evidence from chiefs in rural Malawi". Journal of Public Economics 185:104047.

Berger, Rob. 2020. 5 Breathtaking Numbers Reveal The Unsettling Cost Of Stimulus. https://www . forbes . com/sites/robertberger/2020/10/18/5-big-numbers - reveal - the - unsettlingscope- of - stimulus-spending/?sh=52311045142b.

Borenstein, Severin. 2012. "The redistributional impact of nonlinear electricity pricing". American Economic Journal: Economic Policy 4 (3): 56-90.

Briggs, Ryan. 2021. "Power to Which People? Explaining how electrification targets voters across party rotations in Ghana". World Development 141.

Bruce, Neil, and Michael Waldman. 1991. "Transfers in Kind: Why They Can be Efficient and Nonpaternalistic". American Economic Review 81 (5).

Casey, Katherine. 2015. "Crossing party lines: The effects of information on redistributive politics". American Economic Review 105 (8): 2410-48.

Coady, David, Ian WH Parry, Louis Sears, and Baoping Shang. 2015. How large are global energy subsidies?, 15-105. International Monetary Fund.

Cunha, Jesse M. 2014. "Testing Paternalism: Cash versus In-Kind Transfers". American Economic Journal: Applied Economics 6, no. 2 (): 195-230. https://www.aeaweb.org/articles?id=10. 1257/app.6.2.195.

Cunha, Jesse M, Giacomo De Giorgi, and Seema Jayachandran. 2018. "The Price Effects of Cash Versus In-Kind Transfers". The Review of Economic Studies 86, no. 1 (): 240-281. https : //doi.org/10.1093/restud/rdy018.

Currie, Janet, and Firouz Gahvari. 2008. "Transfers in Cash and In-Kind: Theory Meets the Data". Journal of Economic Literature 46, no. 2 (): 333-83. https://www.aeaweb.org/articles?id= 10.1257/jel.46.2.333.

Dadzie, Christabel Ewuradjoa, and Dhushyanth Raju. 2020. Economic relief through social safety nets during the COVID-19 crisis: the case of Ghana. https : / / blogs . worldbank . org / nasikiliza/economic-relief-through-social-safety-nets-during-covid-19-crisiscase-ghana.

Deutschmann, Joshua W, Agnieszka Postepska, and Leopold Sarr. 2021. "Measuring willingness to pay for reliable electricity: Evidence from Senegal". World Development 138:105209. 
ECG. 2020a. 50\% power rebate: No one will be cheated - ECG. https : //www . ghanaweb.com/ GhanaHomePage/NewsArchive/50-power-rebate-No-one-will-be-cheated-ECG-930226.

- . 2020b. Coronavirus: 'Free' electricity will start May 1 - ECG Boss. http://www.ecggh.com/ index . php/pages/news-events/coronavirus-free-electricity-will-start-may-1-ecgboss.

- . 2020c. COVID-19 power bill relief takes effect. http://www.ecggh.com/index.php/pages/ news-events/covid-19-power-bill-relief-takes-effect.

- . 2020d. COVID-19: ECG asks customers to conserve energy. https://www . businessghana. com/site/news/general/213396/COVID19-ECG-asks-customers-to-conserve-energy.

- 2020e. Govt's free electricity to begin August 2020 - ECG. https : //www . ghanaweb . com/ GhanaHomePage / business / Govt - s - free - electricity - to - begin - August - 2020 - ECG 1022776.

Egger, Dennis, Johannes Haushofer, Edward Miguel, Paul Niehaus, and Michael W Walker. 2019. "General equilibrium effects of cash transfers: experimental evidence from Kenya". National Bureau of Economic Research W26600.

Ferraz, Claudio, and Frederico Finan. 2008. "Exposing corrupt politicians: the effects of Brazil's publicly released audits on electoral outcomes". The Quarterly journal of economics 123 (2): 703-745.

Gadenne, Lucie, Samuel Norris, Monica Singhal, and Sandip Sukhtankar. 2021. In-Kind Transfers as Insurance. Working Paper, Working Paper Series 28507. National Bureau of Economic Research. http://www .nber.org/papers/w28507.

Gentilini, Ugo. 2016. The Other Side of the Coin: The Comparative Evidence of Cash and in-Kind Transfers in Humanitarian Situations? The World Bank.

Gentilini, Ugo, Mohamed Almenfi, and Pamela Dale. 2020. Social Protection and Jobs Responses to COVID-19: A Real-Time REview of Country Measures. http://documents1.worldbank. org/curated/en/467521607723220511/pdf/Social - Protection- and- Jobs - Responses - toCOVID-19-A-Real-Time-Review-of-Country-Measures-December-11-2020 .pdf.

Ghana Statistical Service. 2019. Ghana Living Standards Survey (GLSS) 7 Main Report. https: / / www . statsghana . gov . gh / gssmain / fileUpload / pressrelease / GLSS7 \% 5C \% 20MAIN \% 5C \% 20REPORT_FINAL.pdf.

GhanaWeb. 2020. ECG has no money, don't extend 'free' electricity - Govt told. https: //www . ghanaweb . com / GhanaHomePage / business / ECG - has - no - money - don - t - extend - free electricity-Govt-told-1015783.

Handa, Sudhanshu, Silvio Daidone, Amber Peterman, Benjamin Davis, Audrey Pereira, Tia Palermo, and Jennifer Yablonski. 2018. "Myth-busting? Confronting six common perceptions about unconditional cash transfers as a poverty reduction strategy in Africa". The World Bank Research Observer 33 (2): 259-298.

Haushofer, Johannes, and Jeremy Shapiro. 2016. "The short-term impact of unconditional cash transfers to the poor: experimental evidence from Kenya". The Quarterly Journal of Economics 131 (4): 1973-2042.

Hidrobo, Melissa, John Hoddinott, Amber Peterman, Amy Margolies, and Vanessa Moreira. 2014. "Cash, food, or vouchers? Evidence from a randomized experiment in northern Ecuador". Journal of development Economics 107:144-156.

Hirvonen, Kalle, and John Hoddinott. 2021. "Beneficiary Views on Cash and In-Kind Payments: Evidence from Ethiopia's Productive Safety Net Programme". The World Bank Economic Review 35(2):398-413.

Innovations for Poverty Action. 2020. "Key Decisions for COVID-19 Social Protection in Low- and Middle-Income Countries: Who Benefits and How?" Policy Brief. 
Kahneman, D., J. L. Knetsch, and R. H. Thaler. 1986. "Fairness as Constraint on Profit Seeking: Entitlements in the Market". 76 (4): 728-741.

Khemani, Stuti, James Habyarimana, and Irfan Nooruddin. 2019. What do Poor People Think About Direct Cash Transfers. https: //www . brookings . edu/blog/future-development/2019/04/ 08/what-do-poor-people-think-about-direct-cash-transfers/.

Khera, Reetika. 2014. "Cash vs. in-kind transfers: Indian data meets theory". Food Policy 46:116128.

Klugman, Noah, Joshua Adkins, Susanna Berkouwer, Kwame Abrokwah, Ivan Bobashev, Pat Pannuto, Matthew Podolsky, Aldo Suseno, Revati Thatte, Catherine Wolfram, et al. 2019. "Hardware, apps, and surveys at scale: insights from measuring grid reliability in Accra, Ghana". In Proceedings of the 2nd ACM SIGCAS Conference on Computing and Sustainable Societies, 134144.

Kojima, Masami, Robert Bacon, and Chris Trimble. 2014. "Political economy of power sector subsidies: a review with reference to Sub-Saharan Africa".

Kojima, Masami, and Chris Trimble. 2016. "Making Power Affordable for Africa and Viable for Its Utilities". World Bank Group, Africa Renewable Energy and Access Program, Energy Sector Management Assistance Program.

Komives, Kristin, Vivien Foster, Jonathan Halpern, Quentin Wodon, and Roohi Abdullah. 2008. "Water, Electricity, and the Poor : Who Benefits from Utility Subsidies?" World Bank, no. 20.

Ofori-Atta, Ken. 2019. Budget highlights of the Government of Ghana for the 2020 financial year. https : / / www . mofep.gov . gh/sites / default/files / budget - statements / 2020 - Budget Highlights . pdf.

Sandefur, Justin, Nancy Birdsall, and Mujobu Moyo. 2015. The Political Paradox of Cash Transfers. https://www. cgdev.org/blog/political-paradox-cash-transfers.

Sievert, Maximiliane, and Jevgenijs Steinbuks. 2020. "Willingness to pay for electricity access in extreme poverty: Evidence from sub-Saharan Africa". World Development 128:104859.

Southworth, H. M. 1945. "The Economics of Public Measures to Subsidize Food Consumption". Journal of Farm Economics 27 (1): 38-66.

Strand, Jon. 2013. Political economy aspects of fuel subsidies: a conceptual framework. The World Bank.

Thaler, Richard H. 1999. "Mental accounting matters". Journal of Behavioral Decision Making 12 (3): 183-206. https : / / onlinelibrary . wiley . com/doi / abs / 10 . 1002/\%28SICI\% 291099 0771\%28199909\%2912\%3A3\%3C183\%3A\%3AAID-BDM318\%3E3.0. CO $\% 3 B 2-F$.

The World Bank. 2018. Access to electricity (\% of population). https : //data.worldbank.org/ indicator/EG. ELC. ACCS.ZS?locations=GH.

Whittington, Dale, John Briscoe, Xinming Mu, and William Barron. 1990. "Estimating the willingness to pay for water services in developing countries: A case study of the use of contingent valuation surveys in southern Haiti". Economic development and cultural change 38 (2): 293-311.

Wolfram, Catherine D., Susanna B. Berkouwer, Felipe Vial, Eric Hsu, Oliver W. Kim, and Edward Miguel. 2021. Decomposing Political Favoritism in Kenyan Mass Electrification. Working Paper. 